suspected to play a part in picking out the candidate for druginduced lupus. ${ }^{3}$ Of interest, therefore, was the finding by the group at the Hammersmith Hospital that of 26 patients with hydralazine-induced arthritis, 19 bore the HLA type DR4. ${ }^{18}$ If confirmed, this finding has considerable implications.

\section{GRAHAM R V HUGHES}

Consultant Physician and Senior Lecturer in Medicine,

Rheumatology Unit,

Royal Postgraduate Medical School

London $\mathrm{W} 12$ OHS

1 Perry HM. Late toxicity to hydralazine resembling systemic lupus erythematosus or rheumatoid arthritis. $A m \mathcal{F}$ Med 1973;54:58-72.

2 Blomgren SE, Condemi JJ, Vaughan JH. Procainamide-induced lupus erythematosus. Clinical and laboratory observations. Am f Med 1972; 52:338-48.

${ }^{3}$ Alarcon-Segovia D. Drug-induced lupus erythematosus and related syndromes. In: Rothfield N, ed. Clinics in rheumatic diseases. Vol 1. Philadelphia: Saunders, 1976:573.

4 Levy M, David D. Immune reactions associated with practolol therapy. Int $\mathcal{7}$ Clin Pharmacol Ther Toxicol 1978;16:479-81.

${ }^{5}$ Breckenridge A, Dollery CT, Worlledge SM, Holborow EJ, Johnson GD. Positive direct Coombs tests and antinuclear factor in patients treated with methyldopa. Lancet 1967;ii:1265-7,8.

6 Raftery EB, Denman AM. Systemic lupus erythematosus syndrome induced by practolol. $\mathrm{Br} \mathrm{Med} \mathrm{F} 1973 ; \mathrm{ii}: 452$.

7 Wilson JD, Bullock JY, Sutherland DC, Main C, O'Brien KP. Antinuclear antibodies in patients receiving non-practolol beta-blockers. $\mathrm{Br} \mathrm{Med} \mathcal{F}$ 1978 ; : $: 14-6$.

${ }^{8}$ Cody RJ, Calabrese LH, Clough JD, Tarazi RC, Bravo EL. Development of antinuclear antibodies during acebutolol therapy. Clin Pharmacol Ther $1979 ; 25: 800-5$.

Griffiths ID, Richardson J. Lupus-type illness associated with labetalol. Br Med f 1979;ii:496-7.

10 Bensaid J, Aldigier J-C, Gualde N. Systemic lupus erythematosus syndrome induced by pindolol. $\mathrm{Br} \mathrm{Med} \mathcal{F} 1979 ; \mathrm{i}: 1603-4$.

${ }^{11}$ Harrison T, Sisca TS, Wood WH. Propranolol-induced lupus erythematosus syndrome? Postgrad Med 1976;59:241-4.

12 Lahita R, Kluger J, Drayer DE, Koffler D, Reidenberg MM. Antibodies to nuclear antigens in patients treated with procainamide or acetylprocainamide. $N$ Engl f Med $1979 ; 301: 1382-5$.

${ }^{13}$ Jachuck SJ, Stephenson J, Bird T, Jackson FS, Clark F. Practolol-induced autoantibodies and their relation to oculo-cutaneous complications. Postgrad Med f 1977;53:75-7.

14 Winfield JB, Davis JS. Anti-DNA antibody in procainamide-induced lupus erythematosus. Determinations using DNA fractionated by methylated albumin-Kieselguhr chromatography. Arthritis Rheum $1974 ; 17: 97-110$.

15 Hughes GRV, Rynes RI, Gharavi A, Ryan PEFJ, Sewell J, Mansilla R. The heterogeneity of serologic findings and predisposing host factors in drug-induced lupus erythematosus. Arthritis Rheum $1981 ; 24: 1070-3$.

${ }_{16}$ Mansilla-Tinoco R, Harland SJ, Ryan PJ, et al. Hydralazine, antinuclear antibodies, and the lupus syndrome. $\mathrm{Br} \mathrm{Med} \mathcal{7} 1982 ; 284: 936-9$.

17 Fritzler MJ, Tan EM. Antibodies to histones in drug-induced and idiopathic lupus erythematosus. $\mathcal{F}$ Clin Invest 1978;62:560-7.

18 Batchelor JR, Welsh KI, Tinoco RM, et al. Hydralazine-induced systemic lupus erythematosus: influence of HLA-DR and sex upon susceptibility. Lancet $1980 ; \mathrm{i}: 1107-9$.

\section{Nuclear magnetic resonance imaging and neurology}

In the past decade $x$-ray computed tomography, ${ }^{1}$ CT scanning, has revolutionised investigative practice, has improved diagnostic accuracy in neurology, and is now established as the method of choice for imaging the brain and orbit. CT scanning is also valuable in outlining spinal disorders. ${ }^{2}$ Nuclear magnetic resonance scanning is a more recent development using computed tomography, which when applied to neurology promises to improve clinical imaging techniques and allow the characterisation of tissue and the demonstration of physiological features in vivo.

Nuclear magnetic resonance scanning is a development of conventional nuclear magnetic resonance, which over the past three decades has become a standard method in chemical analysis. Clinical nuclear magnetic resonance imaging uses the magnetic properties of the hydrogen atom nucleus, the proton. The patient is placed in a magnetic field and radiofrequency energy is applied from a coil around the head, so exciting the protons. As the protons subsequently release the energy absorbed, the signal produced is detected as induced electrical currents in a receiver coil. By applying a second magnetic field, or by time-varying the fields, a nuclear magnetic resonance response may be induced from precise locations within the head. The signals are collected and processed by computer in a manner analogous to CT scanning.

Though in a state of development similar to CT scanning several years ago, nuclear magnetic resonance scans are already of such quality that they are directly comparable to CT scans, and recent reports have begun to show the potential of this new imaging process in neurological diagnosis. ${ }^{3-12}$ Several advantages are evident. There is little or no signal from the skull, which appears black on the image, and this lack of signal allows the surface of the adjacent brain to be seen clearly. This feature is particularly useful when structures of the posterior fossa $^{3}{ }^{11}$ and of the parapituitary region are being viewed, ${ }^{5}$ and contrasts with CT scans, where signals from bone may cause artefactual image streaking. White and grey matter may be differentiated to a degree hitherto unattainable using conventional imaging techniques, ${ }^{3} 511$ making it likely that nuclear magnetic resonance will prove a substantial advance in the investigation of cerebral and cerebellar degenerations; toxic, metabolic, and infective encephalopathies; and meningitis. A recent report of the use of nuclear magnetic resonance in multiple sclerosis ${ }^{12}$ showed its discriminative ability to be superior to that of CT scanning. Neoplastic and vascular lesions have been shown, ${ }^{3} 11$ and again preliminary results suggest that nuclear magnetic resonance will prove at least as useful as CT scanning. Imaging of the spinal cord is possible. ${ }^{11} \mathrm{~A}$ further potential advantage has been identified: where there is movement of fluid, such as cerebrospinal fluid in ventricles or blood in vessels, the nuclear magnetic resonance signal is reduced and the image appears black. ${ }^{56}$ This effect can be modified by altering the nuclear magnetic resonance excitation procedure, ${ }^{6}$ so that measurements of blood and cerebrospinal fluid flow may possibly be derived by varying scanning rates and sequences. ${ }^{12}$

The jargon of nuclear magnetic resonance scanning is confusing to the uninitiated. Techniques of scanning and image reconstruction include multiple sensitive point, line scan, spin-lattice relaxation time, spin warp, spin echo, echoplanar, saturation recovery, and projection reconstruction. Which sequence is best suited to a particular clinical problem remains to be evaluated. We can already select more than one form of image presentation to highlight different aspects of the patient. ${ }^{412} 13$ This multiplicity of choice is only one aspect of the versatility of nuclear magnetic resonance. Because the scanning mechanism is entirely electronic, sections can easily be obtained by the operator in any plane-coronal, sagittal, or transverse ${ }^{6}$ - with no discomfort to the patient. At present, scanning times are around two minutes; with modifications this will probably soon be reduced to $15-30$ seconds. $^{9}$

Of at least equal benefit is the seeming lack of hazard to patients. The technique is entirely non-invasive. Radiofrequency photons are non-ionising, so there is no exposure to harmful ionising radiation, and there is no evidence so far that the magnetic fields and gradients used constitute any biological risk. Three potential sources of hazard have been identified: static magnetic fields, changing magnetic fields, and radiofrequency heating. ${ }^{14}$ No permanent side effects have 
been recorded in man up to now. Guidelines for the use of nuclear magnetic resonance in Britain are available from the National Radiation Protection Board. ${ }^{15}$ The theoretical hazards of induction of cardiac fibrillation and cerebral dysrhythmia by currents from rapid magnetic field changes seem remote under present operating conditions. More information is required, however, and people with epilepsy and cardiac disease are not suitable as volunteers. ${ }^{15}$ Heating of metal prostheses by radiofrequency-induced electrical fields is another potential hazard.

Nuclear magnetic resonance imaging has advanced rapidly in a short time. The immediate prospect is of its clinical application as a technique complementary to CT scanning. In the middle distance, provided that costs can be contained and development proceeds apace, it is likely to supersede CT scanning in several diagnostic areas. Over the horizon, the possibility of marrying other nuclear magnetic resonance techniques, such as spectroscopy with imaging, could render less than fanciful the notion of precisely identifying, localising, and monitoring the physiological, metabolic, and pathological features of tissues in vivo, with negligible hazard to the patient. Before the turn of the century?

Consultant Neurologist,

MiLNe ANDERSON

Midland Centre for Neurosurgery and Neurology,

Smethwick, Warley,

West Midlands B67 7JX
${ }^{1}$ Hounsfield GN. Computerised transverse axial scanning (tomography) 1. Description of system. Br $\mathcal{F}$ Radiol $1973 ; 46: 1016-22$.

2 Kreel L. Diagnostic imaging: introduction. Br Med Bull 1980;36:205-8. ్ㅡ

${ }^{3}$ Doyle FH, Gore JC, Pennock JM, et al. Imaging of the brain by nuclear magnetic resonance. Lancet 1981 ;ii :53-7.

+ Edelstein WA, Hutchison JMS, Smith FW, Mallard J, Johnson G, ำ Redpath JW. Human whole body NMR tomographic imaging: normal sections. Br $\mathcal{F}$ Radiol $1981 ; 54: 149-51$.

5 Hawkes RC, Holland GN, Moore WS, Worthington BS. Nuclear magnetic $\overline{\bar{D}}$ resonance $(N M R)$ tomography of the brain: a preliminary clinical $D$ assessment with demonstration of pathology. F Comput Assist Tomogr $\mathbb{D}$ $1980 ; 4: 577-86$.

${ }^{6}$ Holland GN, Hawkes RC, Moore WS. Nuclear magnetic resonance $\varrho$ (NMR) tomography of the brain : coronal and sagittal sections. $\mathcal{f}$ Comput Assist Tomogr 1980;4:429-33.

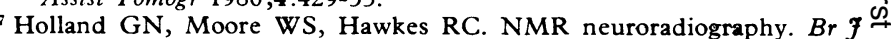
Radiol $1980 ; 53: 253-5$.

${ }^{8}$ Holland GN, Moore WS, Hawkes RC. Nuclear magnetic resonance $\frac{\bar{\sigma}}{\sigma}$ tomography of the brain. F Comput Assist Tomogr 1980;4:1-3.

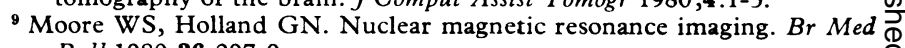
Bull 1980;36:297-9.

10 Moore WS, Holland GN, Kreel L. The NMR CAT scanner: a new look at the brain. CT 1980;4:1-7.

11 Young IR, Burl M, Clarke CJ, et al. Magnetic resonance properties of $\vec{\circ}$ hydrogen: imaging the posterior fossa. AfR $1981 ; 137: 895-901$.

12 Young IR, Hall AS, Pallis CA, Legg NJ, Bydder GM, Steiner RE. $\vec{\omega}$ Nuclear magnetic resonance imaging of the brain in multiple sclerosis. Lancet 1981 ;ii: $1063-6$.

13 Smith FW, Hutchison JMS, Mallard JR, et al. Oesophageal carcinoma demonstrated by whole-body nuclear magnetic resonance imaging. $N$ Br Med f 1981 ;282:510-2.

14 Budinger TF. Nuclear magnetic resonance (NMR) in vivo studies: known ö thresholds for health effects. F Comput Assist Tomogr $1981 ; 5: 800-11$.

15 Nuclear Radiation Protection Board. Exposure to nuclear magnetic resonance. clinical imaging. Harwell, Oxon: NRPB, 1980.

\section{Alcohol: clearing the decks for action}

In the past year we have devoted a great deal of our space to alcohol problems. Daily these are becoming worse; thinking on them has changed dramatically in the past decade; but the response of the Government to them has remained inadequate and uninspired.

The consumption of alcohol has doubled in the past 20 years in Britain, ${ }^{1}$ and as a direct result every form of alcohol damage that can be measured has increased greatly as well. The range of damage is frighteningly wide-affecting individuals' bodies and minds, families, and the social and economic life of every community. ${ }^{1}$ Individual health and social workers have recently been bombarded with information on alcohol problems and are beginning to respond. The Health Education Council and the Scottish Health Education Group are stepping up their alcohol education campaigns. Sadly, however, until now the response by the voluntary organisations and the Government has been poor, but the recent report by a Department of Health and Social Security study group on the voluntary organisations concerned with alcohol abuse ${ }^{2}$ ( $p$ 1392) may usher in a new era.

The report is strongly critical of the existing voluntary organisations, all of which receive money from the department - that is, the National Council on Alcoholism, the Medical Council on Alcoholism, the Alcohol Education Centre, and the Federation of Alcoholic Rehabilitation Establishments. It suggests that they should be disbanded with a new organisation being created to do the work of all four. Mr Kenneth Clarke, the new Minister of Health, has called for reactions to the report by the end of June. The weakness, rivalry, and overlap of work of the four have long been recognised by those concerned with alcohol problems, and we welcome the idea of a new organisation that will allow a new start as well as a rationalisation of the work. The report makes further suggestions, which we also support: that the medical royal colleges should do more to educate doctors on alcohol problems, and that they should set up a new pressure group-a kind of alcohol equivalent to Action on Smoking and Health. $\stackrel{2}{\Rightarrow}$ Discussions have been going on for over a year on forming this $\frac{O}{3}$ campaigning organisation, and the time certainly seems ripe for it to be born.

We need such a group because the Government continues to be equivocal in its response to alcohol problems. The drink trade is rich and powerful and supplies the Government with:much needed revenue, jobs, and exports ( $p$ 1392). The 3 . Government is thus understandably unwilling to take strongo action to reduce alcohol consumption, but if we are to have fewer alcohol problems then we as a nation must drink less, 음 and the Government should adopt policies to ensure that this $N$ happens. The much discussed Central Policy Review Staff $>$ (the "think-tank") report of 1979 suggested a coherent policy․ㅡ․ for the Government, but the report has never been published. N Instead, we have been given the much criticised Drinking $\mathrm{W}^{2}$ Sensibly. ${ }^{3}$ We join with the British Fournal of Addiction ${ }^{4}$ in advocating publication of that "think-tank" report, which wee at the $B M \mathcal{F}$ have seen and admired. As a matter of urgency the Government should take up the policies that this report ${ }^{+}$ suggests, and in particular it should establish an interdepart- $\frac{0}{0}$ mental committee and forge a coherent policy on alcohol.

1 Special Committee of the Royal College of Psychiatrists. Alcohol and alcoholism. London: Tavistock Publications, 1979.

2 Department of Health and Social Security. National voluntary organisations and alcohol misuse. London: DHSS, 1982.

${ }^{3}$ Department of Health and Social Security. Prevention and health: drinking sensibly. London: HMSO, 1981.

4 Anonymous. Public interest. Br $\mathcal{F}$ Addict 1982;77:1-2. 